\title{
POST OBSTRUCTIVE PULMONARY EDEMA AFTER ATTEMPTED NYLON ROPE SUICIDAL HANGING
}

Rakesh Nigam¹, S. Chatterjee², M. Murthy33, D. Kosam4, M. Debbarma ${ }^{5}$

\section{HOW TO CITE THIS ARTICLE:}

Rakesh Nigam, S. Chatterjee, M. Murthy, D. Kosam, M. Debbarma. "Post Obstructive Pulmonary Edema after Attempted Nylon Rope Suicidal Hanging”. Journal of Evolution of Medical and Dental Sciences 2015; Vol. 4, Issue 47, June 11; Page: 8239-8241, DOI: 10.14260/jemds/2015/1194

\begin{abstract}
Survival after nylon rope suicidal hanging is a rare occurance. We describe here a patient who attempted suicide by nylon rope hanging and developed post obstructive pulmonary edema was managed successfully. Patient recovered completely with ventilatory support in next 60 hours without any neurological deficit.This case highlights an unusual complication of hanging and its recovery.
\end{abstract}

KEYWORDS: Post obstructive pulmonary edema,cerebral edema, Nylon rope attempted suicidal hanging.

KEYMESSAGES: Patient was lucky enough to be rescued and brought to the hospital early, even after nylon rope attempted suicidal hanging. Such cases need to be managed aggressively as there are chances of their complete recovery

INTRODUCTION: Depression is increasing at an alarming rate globally. $(1,2,3)$ Hanging is one of the oldest and common mode of suicide in the young adults. Death takes about 8-10 minutes in such cases.(4) The mortality and morbidity change dramatically if such patients are rescued early and managed aggressively, even in small ICUs. Here we report a case who presented in severe pulmonary and cerebral edema after attempted suicidal nylon rope hanging.

CASE HISTORY: A 24 years old male of average built was rushed to ICU with a history of attempted nylon rope suicidal hanging. On initial examination he was cyanosed, with laboured respiration and froth coming out from mouth and nose. He was very irritable, tossing on the bed, moving all four extremeties. His pulse rate was 130 /minute, blood pressure $160 / 110 \mathrm{~mm}$ of hg and spo 2 of $70 \%$ on air. He did not respond to verbal commond but pupil were bilaterally constricted reacting to light. A ligature mark was clearly visible around the neck [Figure1].

He was gently intubated with propofal and butorphenol given intravenously. Ventilation was initiated on ventilator, with a tidal volume of $500 \mathrm{ml}$, FIO2 $100 \%$ \& PEEP of $10 \mathrm{~cm}$ of water in SIMV mode. Chest auscultation revealed bilateral extensive coarse crepitations and cardiovascular evaluation revealed sinus tachycardia. On neurological examination there were bilateral brisk deep tendon reflexes and planters were upwards. Intravenous Mannitol 100ml and dexamethasone 8mg 8hourly given. Midazolam and butorphenol was given in multiple the required doses intravenously. $\mathrm{FIO}_{2}$ was gradually reduced to $40 \%$ and PEEP to $5 \mathrm{~cm}$ of water in the next 24 hours as the chest became relatively clear and spo 2 improved to $95 \%$.

Day 2- He was heamodynamically stable, responding to painful stimuli, but Sedated. $\mathrm{FIO}_{2}$ was further reduced to $35 \%$ and PEEP maintained at $5 \mathrm{~cm}$ of water. Third day mannitol was stopped, weaning from ventilator was started and extubated in the evening (after 60 hours). He was given 02 by face mask for next 12 hours and was maintaining saturation above $95 \%$ later, on room air. X ray neck taken next day showed no bony fracture, but narrowing of trachea up to C-6. (Figure 2) MRI was 
not available in our institution, but neurological examination was normal now. His voice was hoarse and indirect laryngoscopy showed sluggish movement of vocal cards with a phonation gap. There was no problem in deglutition, and he could eat both solid and liquids. He was discharged with advice of vocal rest and, anti-inflammatory enzyme. After Two weeks follow up, showed his voice has improved and was referred for psychiatric consultation.

DISCUSSION: Survival without any morbidity after nylon rope attempted suicidal hanging is rare in literature. In a series of twenty cases of attempted suicidal hanging, two of their patient used plastic ropes. In both the cases, brain stem reflexes did not return and both patient died eventually.(5)

Postobstructive pulmonary edema (POPE; also known as negative pressure pulmonary edema) is a potentially life-threatening complication in which pulmonary edema occurs shortly after the relief of an upper airway obstruction. The incidence of POPE has been reported to be as high as 1 in 1000 general anesthetic cases and commonly presents as acute respiratory distress that requires immediate intervention.(6) Acute post obstructive pulmonary edema may complicate extubation perioperatively, when severe laryngo spasm occur in adults. ${ }^{(7)}$ Though the pathogenesis of pulmonary edema appear to be multifactorial, in our case but the primary factor being markedly negative intrapleural pressure associated with upper airway obstruction.(8)

In our patient it appears that attempted hanging with nylon rope caused severe degree of mechanical airway obstruction, attempts at breathing against it led to severe degree of negative intrapleural pressure resulting in post obstructive pulmonary edema. Our patient remained heamodynamically stable throughout, and there were no ECG changes suggestive of any ventricular hypokinesia as was observed in another case report.(9)

Cerebral edema is the result of compression of jugular vein leading to congestion in the brain. Hypoxia due to pulmonary edema was also a contributing factor. All this manifested in irritable behaviour and low GCS on admission, showed a good response to mannitol, steroid and hyperventilation. X-ray neck taken later on after extubation showed narrowing of trachea from $\mathrm{C} 2$ to C5 level but no bony injuries.

Hoarseness of voice may be the end result of neuropraxia of recurrent laryngeal nerve due to transient compression caused by nylon rope which improved after vocal rest and anti-inflammatory treatment.

CONCLUSION: Attempted suicidal hanging has got a very high mortality and morbidity. Irrespective of the initial general assessment, aggressive and early resuscitation and management can save life of such patients.

\section{REFERENCES:}

1. Yilmaz TA, Riecher-Rössler A: Suicide attempts among first and second generation immigrants (in German). Neuropsychiatrie 2008; 22: 261-267.

2. Chandrasena R, Beddage V, Fernando ML: Suicide among immigrant psychiatric patients in Canada. Br J Psychiatry 1991; 159: 707-709.

3. Soni Raleigh V, Balarajan R: Suicide and self-burning among Indians and West Indians in England and Wales. Br J Psychiatry 1992; 161: 365-368. 


\section{CASE REPORT}

4. Kumar M, Mandhyan R, Shukla U, Kumar A, Rautela RS. Delayed Pulmonary Oedema Following Attempted Suicidal Hanging - A Case Report. Indian J Anaesth 2009; 53: 355-7.

5. Padhiary KN, Panda J, Das S. Observation of cases of hanging treated in medical wards. JAPI 2003; 51: 427.

6. Udeshi A., Cantie S. Michael, Pierre E. Postobstructive pulmonary edema Journal of Critical Care 2010; 25: 538-538.

7. Scott A. Lang, Peter G. Duncan, Hung C. Ha. Pulmonary oedema Associated with airway obstruction. CAN J ANAESTH 1990; 37: 210-218.

8. Chacko J, Brar G, Elangovan A, Moorthy R. Apical ballooning syndrome after attempted suicidal hanging. Indian J Crit Care Med 2011; 15: 43-5.

9. Parikh CK, Parikh text book of medical jurisprudence forensic med and toxicology, 6th edition, CBS publishers New Delhi, 2002; 3.33-3.40.

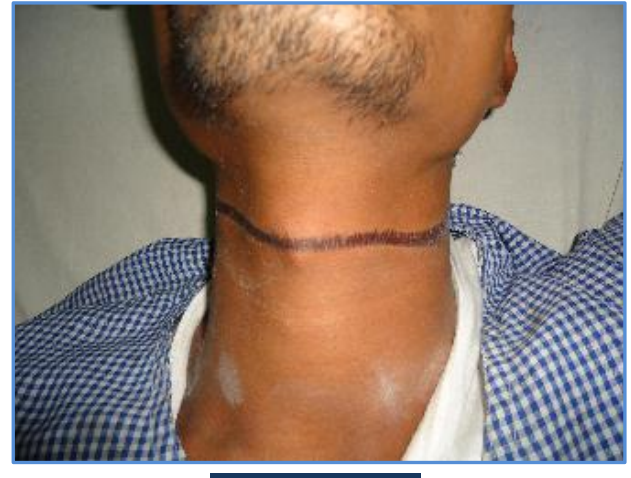

Figure 1

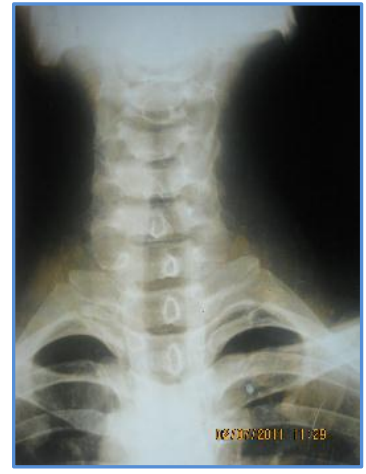

Figure 2

\section{AUTHORS:}

1. Rakesh Nigam

2. S. Chatterjee

3. M. Murthy

4. D. Kosam

5. M. Debbarma

\section{PARTICULARS OF CONTRIBUTORS:}

1. Associate Professor, Department of Anaesthesiology, Chhattisgarh Institute of Medical Sciences, Bilaspur.

2. Professor, Department of Anaesthesiology, Chhattisgarh Institute of Medical Sciences, Bilaspur.

3. Associate Professor, Department of Anaesthesiology, Chhattisgarh Institute of Medical Sciences, Bilaspur.

FINANCIAL OR OTHER COMPETING INTERESTS: None
4. Assistant Professor, Department of Anaesthesiology, Chhattisgarh Institute of Medical Sciences, Bilaspur.

5. Assistant Professor, Department of Anaesthesiology, Chhattisgarh Institute of Medical Sciences, Bilaspur.

\section{NAME ADDRESS EMAIL ID OF THE} CORRESPONDING AUTHOR:

Rakesh Nigam, \# 23, Om Garden, Parijat Colony, Neharu Nagar, Bilaspur, Chhattisgarh.

E-mail: bangonigam@gmail.com

Date of Submission: 19/05/2015. Date of Peer Review: 20/05/2015. Date of Acceptance: 04/06/2015. Date of Publishing: 11/06/2015. 